\section{International Branch}

\section{Campuses and Institutional Control}

\section{Robert Coelen}

Robert Coelen is Professor of Internationalisation of Higher Education at Stenden University of Applied Sciences, in the Netherlands. E-mail: robert.coelen@stenden.com.

$\mathrm{T}$ he development of institutional mobility has seen a rapid increase from about 20 or so international branch campuses (IBCs), at the turn of the century to about I2 times that number in 2013. Even so, the proportion of higher education institutions that has IBCs remain at only about I percent of the global population of higher education institutions.

Motivationss for establishing international branch campuses include push and pull factors. Push factors that have been widely described include: economic, reputational, or academic opportunities, soft-diplomacy, and internationalization. Pull factors include economic rationales, additional educational opportunities, building research capability, and rapid adjustment of education to meet requirements of today's employers.

The academic rationales from the home institution include aspects such as the opportunity for home institution staff to teach in another cultural context, the codevelopment of curricula with staff from IBCs, and for students to study at an IBC within the paradigms of the education offered by the home institution. A smooth credit transfer and good integration in the home program should characterize such opportunities.

\section{Curricular Changes}

IBCs provide a good opportunity for codevelopment of the curriculum. Issues of a practical, jurisdictional, or cultural nature will arise in the delivery of the original home curriculum. This may give rise to changes that have to be implemented. Such changes may become adopted by the home program and lead to a more robust curriculum for all delivery points.

These curricular changes highlight an aspect of IBCs, which takes a lot of resources, care, and foresight-or sometimes repair in hindsight. It is unlikely that a program can just be mobilized from the home campus to an IBC without adaptation. Even at the most basic operational level, there will be changes. This is, of course, generally accepted and understood. However, if the IBC students are to receive a degree that is indistinguishable from that of the home campus, this can only occur if the achieved learning outcomes are of the same nature and standard as at the home campus.

\section{Factors Affecting Institutional Control}

This brings into focus the mechanisms that must be present to ensure quality control. In the development of an IBC for a particular institution this often entails the careful scrutiny and adaptation of quality control mechanisms (both internal and external) that are designed to operate in one jurisdiction (the home country) to those that will also work in the host country. The host country environment, or barriers between the two campuses, may affect the efficacy of such quality-control mechanisms.

A simple example of issues at the home campus affecting the level of control relates to the existence of these perceived campus barriers. The attention of a faculty to the program(s) under its control at a branch campus may be far less than that at the home campus. This can lead to the two deliveries becoming out of step, in terms of content or educational methods, etc. The pressures on staff may be such that the delivery of learning materials may be on time for the home campus, but too late for an orderly consideration by the branch campus to cope with even logistical changes that have to be made. Such seemingly innocuous problems may cause members of staff at IBCs to feel disenfranchised. Trust may become lost between the two groups, thereby further reducing commitment and effective communication. Undesirable changes to the delivery may go unnoticed until too late.

\section{Balancing the perspectives of the vari- ous stakeholders in a presently expand- ing transnational education remains a difficult issue.}

The transnational delivery of an educational program, at an IBC or in some other arrangement, subjects the delivery and the content to the laws and regulations of another jurisdiction. This may jeopardize the integrity of the program, or at least necessitate modifications to the original curriculum, which in turn could affect quality. Sometimes definition differences cause apparent problems.

An example is provided by a case where a program developed under the European standard of 6o ECTS per annum (representing I,680 hours of total academic workload) was submitted for accreditation in South Africa. This 
was locally considered to be above their standard maximum academic load. Differences in the definition of academic workload were at the basis of this problem. Careful scrutiny resolved the issue without materially affecting the program.

There are jurisdictions where the undergraduate program must contain elements that are unique to the country. Often these courses relate to issues of national identity. The easy way out would be to use the elective space in a program. This, however, does affect the students' ability to avail themselves of a wider range of elective program components that would otherwise be possible.

A much more complex situation could arise when an IBC is the result of a partnership in which the partners have different objectives. The importance of alignment on this aspect cannot be understated. There are good examples of just how calamitous a clash between academic and economic objectives can be. The conflict between the need for program viability versus academic standards may lead to the IBC's closure or a move. The insistence of upholding certain standards by the University Quality Assurance International Board caused several IBCs to be excluded from operating in Dubai. The solution in this case was to move to another emirate in the United Arab Emirates where no such quality-control method existed.
Notwithstanding carefully worked out agreements, differences in objectives of partners may also lead to tension about the need for investments in the academic process (i.e., financial control). Lack of investment may cause program delivery at an IBC to become inferior to that at the home campus, with attendant quality-assurance concerns.

\section{Transnational Quality Assurance}

Various home and host countries have organizations in place to ensure adherence to quality standards. The United Kingdom and Australia, as sending countries, have quality agencies that include transnational delivery in their scope. In the Netherlands, this is excluded from the purview of the Dutch Flemish Accreditation Organisation. Host countries have variously created regulations to provide a measure of control. Transnational education is a relatively new phenomenon and required legislative changes lag behind.

Balancing the perspectives of the various stakeholders, in a presently expanding context for transnational education, remains a difficult issue. The divergent issues on this matter have thus far prevented India from introducing legislation covering this arena. IBCs come and go. In the risk-averse world of higher education it remains to be seen whether they will continue to expand.

\section{News Of the Centers}

\section{CHEI}

From the Centre for Higher Education Internationalisation (CHEI) in Milan, Hans de Wit and Fiona Hunter are currently leading the Study on Internationalisation of Higher Education for the European Parliament, in cooperation with the International Association of Universities (IAU) and the European Association for International Education (EAIE). Fiona Hunter is coordinating an evaluation of the internationalization strategy of the Università Cattolica del Sacro Cuore.

Hans de Wit is a member of the Steering Committee of the project of the International Association of Universities (IAU) and UEFSCDI in Romania concerning internationalization of higher education in Romania. Fiona Hunter is also one of the experts on this project. Hans de Wit is a member of the Scientific Committee and Editorial Board of the second edition of the Bologna Process Researchers' Conference, to be held in Bucharest on November 24-26, 2014, where Fiona Hunter will also present a paper on internationalization as a change agent, the case of Italy.

Hans de Wit is a consultant, on an initiative titled "Advancing Models of Best Practice in Internationalization of Higher Education in Kazakhstan," for the Graduate School of Education of Nazarbayev University in Kazakhstan. CHEI is also involved in "Internationalization of Italian Higher Education," a study and analysis by Roberta de Flaviis, a fulltime doctoral student, in coordination with Fiona Hunter and Hans de Wit.

With the development of higher education internationalization as a priority for institutions around the world, the demand for expert training and research in the field has increased over the last decade. CHEl has developed a doctoral program for aspiring researchers and professionals in higher education internationalization. CHEl's doctoral program is a " $1+3$ " program, involving one preparatory year followed by three years of research, and is exclusively focused on the internationalization of higher education. Currently, there are 5 doctoral students, two from the United States and three from Europe, participating in the program; several other students, including from Latin America and Africa, are participating in the preparatory year.

The CHEI Research Training Seminar brings together senior researchers, international education practitioners and aspiring researchers to discuss current research topics, develop research proposals and develop their methodological and analytical skills. Through the seminars, CHEI is developing a knowledge community in higher education internation- 